\title{
Genito Urinary Syndrome of Menopause (GSM) or Vulvo-vaginal Atrophy (VVA) an Unspoken Sorrow
}

\author{
Shaikh Zinnat Ara Nasreen ${ }^{1}$, Safinaz Shahreen ${ }^{2}$, Saleheen $\mathrm{Huq}^{3}$, Sabereen $\mathrm{Huq}^{4}$ \\ ${ }^{1}$ Obs/Gyne Department, Z. H. Sikder Women's Medical College \& Hospital, Dhaka, Bangladesh \\ ${ }^{2}$ Obst/Gyne Department, Watford General Hospital, London, UK \\ ${ }^{3}$ Internal Medicine Department, Peterborough General Hospital, Peterborough, UK \\ ${ }^{4}$ Urology Department, Uclh Hospital, Euston Road, London, UK
}

Email address:

zinnatn@yahoo.com (Shaikh Z. A. N.), safinaz.shahreen@doctors.org.uk (Safinaz S.), saleheen.huq@nhs.net (Saleheen H.), drsabereenhuq@gmail.com (Sabereen H.)

\section{To cite this article:}

Shaikh Zinnat Ara Nasreen, Safinaz Shahreen, Saleheen Huq, Sabereen Huq. Genito Urinary Syndrome of Menopause (GSM) or Vulvo-vaginal Atrophy (VVA) an Unspoken Sorrow. American Journal of Internal Medicine. Vol. 7, No. 6, 2019, pp. 154-162. doi: 10.11648/j.ajim.20190706.14

Received: August 19, 2019; Accepted: September 26, 2019; Published: December 2, 2019

\begin{abstract}
GSM includes wide spectrum of vulvovaginal Symptoms and urinary troubles replacing the term vulvovaginal atrophy (VVA). It is a silent epidemic condition affecting 50-60\% postmenopausal women. Estrogen withdrawal causes thinning, narrowing, tissue loss \& reduced blood supply in vulvo-vaginal area, which results GSM. GSM causes burning in vagina, dyspareunia, urinary urgency, repeated UTI. Dyspareunia affects all the domain of sexual function and deteriorates the quality of life. Irony is, women are oblivious to share and doctors are reluctant to discuss. So women keep continue suffering without knowing the restorative treatment. Repercussion of GSM/VVA intensifies the sorrows, distress and sufferings. It has profound effect on relationship and psychology and quality of life of women. Good history taking and clinical examination do diagnosis. Investigations are done to exclude other causes. Treatment is challenging. Maintenance of optimum body weight, exercise, regular coitus, quitting smoking \& excessive alcohol intake are the key factors. Vaginal moisturizers are recommended as 1st line therapy for mild to moderate VVA or women who can't take estrogen. Ideal moisturizers should have similarity with vaginal secretion of osmolality, $\mathrm{pH}$ and composition. Meta analysis shows local estrogen therapy is effective. It restores vaginal $\mathrm{pH}$ and maturation index. Systemic absorption is minimal so progesterone needs not to be added. Testosterone improves dyspareunia, sexual desire, lubrication and satisfaction. DHEA (Prasterone) penetrates vaginal wall better. It increases elasticity and vascularity of vagina. RCTs have not shown benefits of it's systemic therapy. But local daily administration of DHEA reduces dyspareunia and GSM so improves the quality of life. Ospemifene is well tolerated. It's agonist effect on vaginal mucosa and antagonist effect on endometrium and breast, makes it promising. Lasofoxifene, third generation SERM, is also very effective but it needs FDA approval. Laser is widely being used and very effective. It is simple, faster, painless procedure. It activates dominant fibroblasts, proteoglycans, hyaluronic acid, thereby improves GSM \& sexuality. Black cohosh, Botox, G-shot, probiotics, gabapentin are not yet evidence based. Still there is significant unmet need for medical treatment. Women reports GSM but that is only tip of iceberg. Good communication and optimum treatment only can break the sorrows GSM/VVA.
\end{abstract}

Keywords: Genitourinary Syndrome of Menopause, Vulvovaginal Atrophy, Estrogen Cream, DHEA Cream, Laser Therapy, SERM

\section{Introduction}

Menopause is associated with an arrest of ovarian synthesis of estrogen, progesterone and dehydroepiandrosteron (DHEA) [1]. Loss of steroid hormones causes physical changes that interfere with normal sexual and genitourinary functioning in a significant number of postmenopausal women [2]. Vulvo-Vaginal Atrophy 
(VVA) or dryness of vagina and vulva are the result of estrogen deficiency, it may be the problem at any age, but it occurs more frequently in women beyond menopause. VVA is a silent epidemic that affects up to $50 \%-60 \%$ of postmenopausal women. In US two third women suffer from VVA in their lifetime [3].

Women spend more than one-third of their lives in the postmenopausal state. Over half of postmenopausal women experience GSM [4] and more than $75 \%$ reports an impact on their sexual lives. This VVA is important determinant of Quality of life and sexual well being for menopausal women [5]. Although the symptoms are diverse, the prevalence is high [6], the health and quality of life in postmenopausal women are seriously influenced by GSM and GSM is associated with sexual dysfunction [7]. As 70\% women think it is natural during menopause so they do not turn to doctor and suffer in silence. Moreover many women think the symptoms will subside over time or attribute them to a natural part of aging. Survey revealed that only $20-25 \%$ of women with GSM seek medical attention [8]. We looked at recent metaanaaalysis, we searched pub med, Cochrane database, AJOG, BJOG, Elsiver, fertl; steril, menopause journal, Climacteric journal.

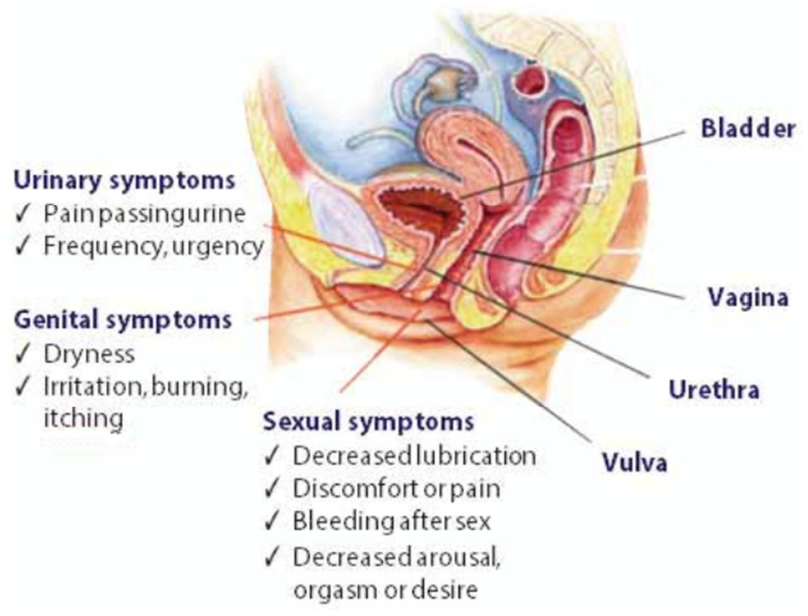

(Curtsey of LECOM- Obs/Gyne, March 3, 2018)

Figure 1. Anatomy of Female Genito urinary system.

\section{Symptoms/Signs of GSM}

The GSM focuses on vaginal atrophy, sexual discomfort and urinary problems.

\subsection{Symptoms}

GMS includes vaginal soreness, vaginal pain, burning, itching in vagina and mild discharge, overall vaginal discomfort and severe dyspareunia [9, 10]. Also GSM/VVA is associated with frequency, urgency, dysuria, nocturia and urge incontinence. As VVA is inadequate to describe the range of menopausal urogenital symptoms, the International society for the study of Women's Sexual health and the NAMS proposed the term GSM (Genitourinary syndrome of menopause) instead of VVA [11]. The term GSM is new nomenclature of VVA, which provides a broader description of the genitourinary effects of estrogen withdrawal at menopause and remove the negative stigma of dryness for women. GSM/VVA is a more accurate and inclusive term that describes the multiple changes occurring in the external genitalia, pelvic floor tissues, bladder and urethra, and the sexual function and libido, caused by hypo-oestrogenism during the menopause transition and post menopause. GSM has also been adopted as VVA which encompasses symptoms and signs such as changes in the labia majora or minora, clitoris, vestibules/introitus, vagina, urethra and bladder associated with decreased estrogen and other sex steroids so treatment need to start early to prevent irreversible tissue atrophy $[12,13]$. GSM/VVA can start in perimenopause, increase during the early menopause and further increase few years after menopause, the symptoms range in severity from mildly bothersome to unbearable [14].

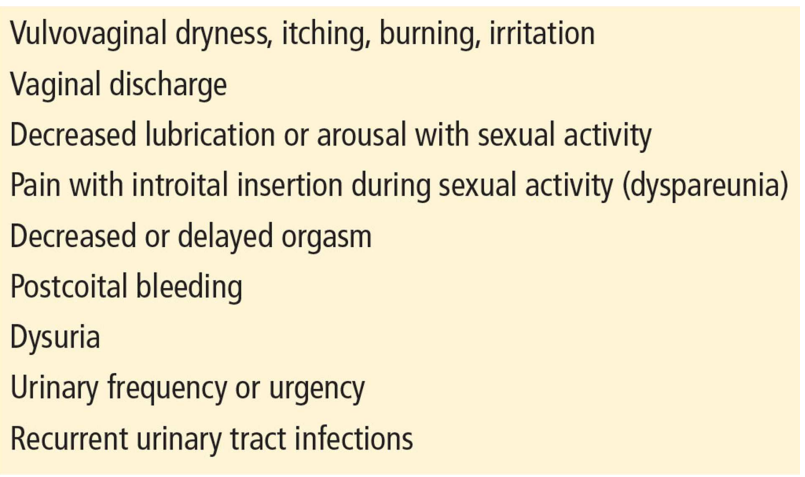

Ref: Cleveland clinic journal of medicine, may 2018

Figure 2. Genitourinary syndrome of menopause: Clinical symptoms.

\subsection{Anatomical Changes Responsible for the Symptoms}

Unlike Vasomotor symptoms GSM /VVA does not resolve spontaneously; rather there is a progressive and cumulative negative effect over the time [15]. Long-term therapy may be necessary to maintain urogenital health [16]. Due to aging and the changed hormonal milieu, menopause encompasses VVA, urinary and pelvic manifestation associated with and further potential etiology. Also lack of sex steroid during menopause causes decrease in the proportion of superficial cell and an increase in the proportion of immature parabasal cells [17]. GSM or VVA affects half of menopausal women contributing severe sexual dysfunction. Dryness of vagina produces severe dyspareunia, which again results poor arousal, impaired orgasm and consequently reduced sexual satisfaction. Women having VVA or GSM symptoms also frequently suffer from sexual dysfunction [18], vasomotor symptoms, depression and have multiple co-existing conditions, such as osteoporosis and urinary incontinence $[19,20]$.

Anatomical modification related to GSM includes- thinning of vaginal mucosa, mucosal dryness, atrophy of elastic and collagen tissue with reduced blood supply. Menopause results altered appearance and function of smooth muscle cells, increased density of connective tissue and fewer blood vessels, 
an increase of vaginal $\mathrm{pH}$, which is an index of poor vaginal epithelium maturation, indicates estrogen deficiency and it results chronic VVA or GSM, [21, 22]. There is also changes in vaginal flora associated with the loss of superficial cells, glycogen, and lactobacilli result in increase $\mathrm{pH}$ and the increased potential for vaginal and urinary tract infection and inflammation. Decreased in vaginal blood flow and lubrication often result in dryness and dyspareunea [23]. The reduced blood supply and less elasticity make the vagina prone to petechial, injury and pain [23].

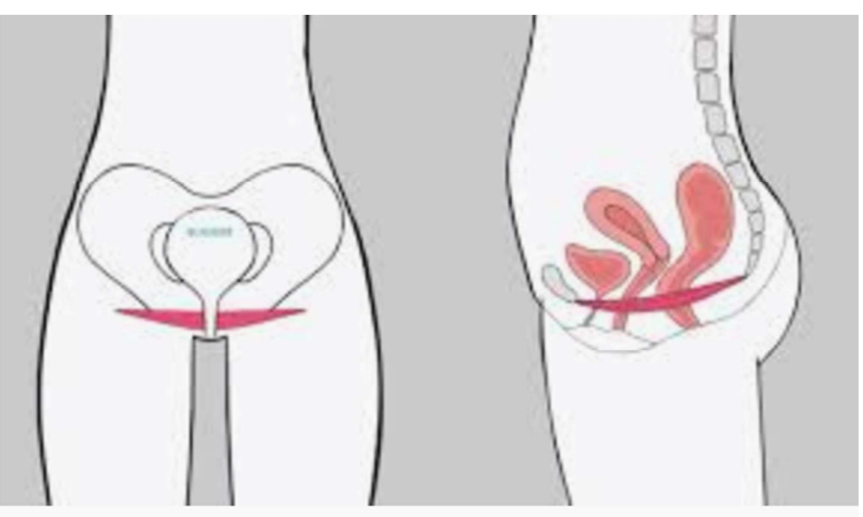

Figure 3. Impact of menopause on pelvic floor.

\subsection{Effect of Estrogen Deficiency}

Estrogen withdrawal cause thinning, narrowing, shrinkage of blood supply, decreases lubrication and severe dyspareunia again single entity of dyspareunia deteriorates all the domain of female sexual function such as low desire, poor arousal, orgasm and reduced sexual satisfaction.

In addition, under condition of estrogen deficiency, there is disruption of the balance of the vaginal microbial, the pathogenic gram-negative fecal flora and other bacteria prevail in its composition, and instead of acidic the vagina develops alkaline $\mathrm{pH}$, which causes more deterioration of VVA or GSM.
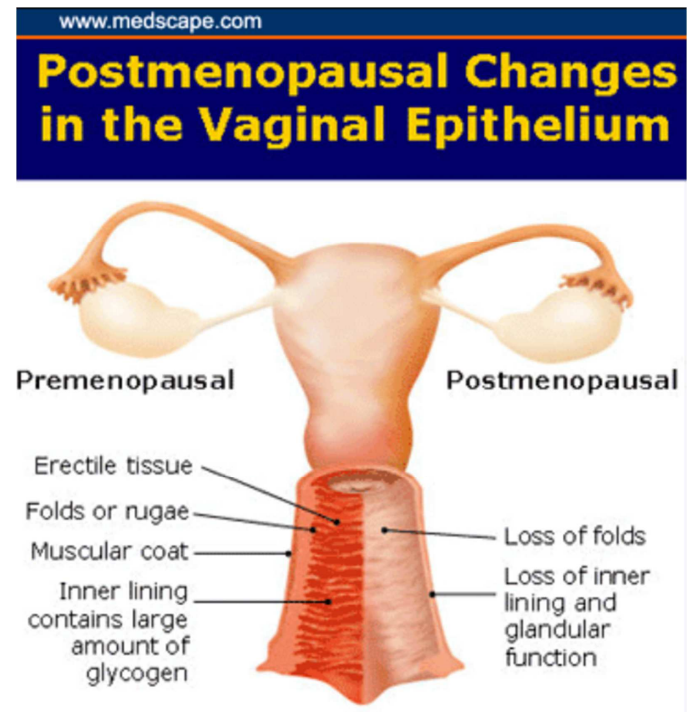

Figure 4. Changes of vaginal mucosa due to estrogen deficiency.
The repercussion of these symptoms on quality of life often makes it necessary to initiate treatment immediately otherwise this condition becomes chronic and progressive and devastating.

VVA or GSM brings disharmony in conjugal life; it has significant impact on women's sexuality and quality of life [24]. Despite high prevalence and associated burden, GSM/VVA is often inadequately identified and addressed $[25,26]$. GSM/VVA is often ignored by women and overlooked by health providers or doctors. Women feel embarrassed to address VVA and this embarrassment seems to be reinforced by the perceived lack of interest of the doctors, also doctors don't take consideration the impact of GSM/VVA on women's quality of life [27, 28].

Though estrogen deficiency of menopause is the leading causes of GSM/VVA, but health providers need to exclude other causes of GSM or VVA; other causes are-Cigarette smoking, Breast feeding, Puerperium, Oophorectomy, Sjograns syndrome, Drugs, Radiotherapy, Infection by Bacteria, yeast and parasite.

\section{Diagnosis of GSM/VVA}

It is important to ask questions about GSM whenever postmenopausal woman comes for any check-up.

\subsection{History Taking and Physical Examination}

These are necessary to exclude all the other causes of VVA than menopause. Minimum investigations are required. Women are oblivious about the symptoms even the VIVA (vaginal health; insight, views \& attitude) survey showed that responders had very little knowledge about vaginal atrophy [29]. Both the health care providers (HCP) and the patients find vaginal symptoms to be a sensitive topic can be difficult to discuss [30], as evidenced by numerous surveys [31]. Only $36 \%$ of HCP in the Revealing Vaginal Effects at Mid Life (REVEAL) survey indicated that they discuss vaginal pain associated with sex with their patients [32]. So IMS (International menopause society) recommended, that all the Doctors and HCP need to be proactive in detail history taking pointing towards GSM.

\subsection{Negative Impact on Relationship}

The Revive (Real women's views of treatment options for menopausal vaginal changes) survey of 3046 postmenopausal women with GSM showed VVA has negative impact on the ability to be intimate $62 \%$, to enjoy sexual intercourse enjoyment $65 \%$, to be intimate $61 \%$, women's relationship with partner $55 \%$ and sexual spontaneity $54 \%$ [33].

\subsection{Impact of GSM on Sexuality}

CLOSURE (Clarifying Vaginal Atrophy's impact on Sex and Relationship) survey of postmenopausal women in North America, vaginal discomfort was reported to cause participants to avoid intimacy $58 \%$, experiencing loss of libido $64 \%$, experiencing pain associated with sex $64 \%$ and 
to stop having sex $30 \%$ [34]. The painful ramifications of vaginal atrophy, leads severe inferiority complex, low selfesteem and depression. Women are oblivious and reluctant to discuss the issue so empathetic and proactive history taking focusing on this particular issue is again very important. Physical examination reveals the atrophic changes of vulva and vagina.

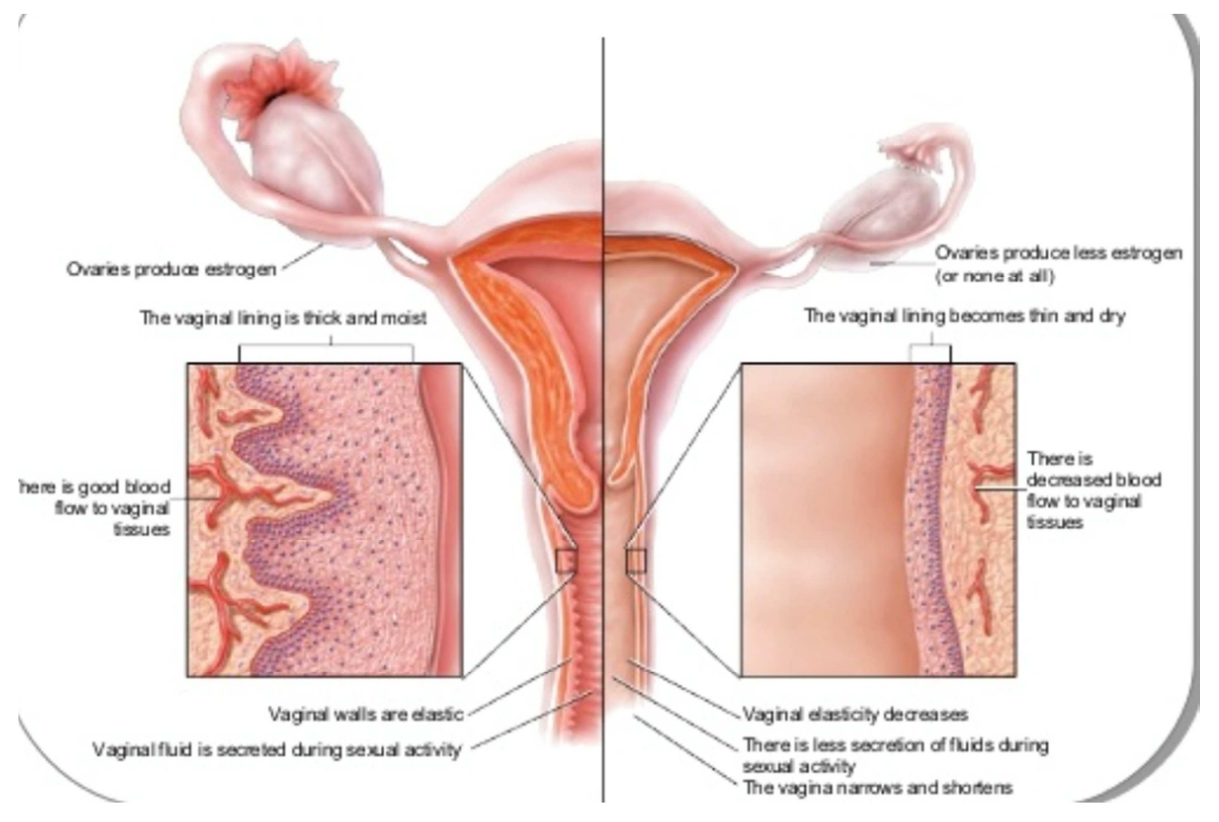

Figure 5. Physical examination reveals the changes of vagina (curtsey of women's health).

Investigations are done only to exclude the other causes. Maturation index and $\mathrm{pH}$ estimation may be done, but it is not essential. If $\mathrm{pH}$ is $>5.5$ with in vagina, it indicates VVA. Routine examination of Urine needs to be checked. Other tests should be done according to the necessity.

\section{Treatment of GSM/VVA}

Treatment depends on the severity of the symptoms of the disease and the preference and expectation of women. The main goal of the treatment is to improve and ameliorate the symptoms of VVA and to restore the anatomical changes to prevent the progression of the disease process. Treatments include;

General treatment, Hormonal Treatment, Non Hormonal therapy.

\subsection{General Treatment}

Maintenance of optimum body weight, doing regular exercise, yoga, meditation and having optimum nutrition and regular coitus practice, which improves GSM in some extent. Women also must be advised to quit smoking and drinking too much alcohol. Regular Exercise, pelvic floor physiotherapy improves GSM/VVA by increasing the blood flow in the perineum. Positive Attitude of women towards menopause (Swan Study) and awareness causes mental conditioning of menopausal symptoms. Along with general treatment, stepwise treatment based on symptoms severity with both hormonal and nonhormonal options are recommended for women with symptoms specially related to sexual activity [35].

\subsection{Lubricants and Moisturizers}

For mild and moderate VVA $1^{\text {st }}$ line recommendation is lubricants and moisturizers. Regular sex activity is also advised along with lubricants. Moisturizers or lubricants are good alternative to estrogen cream. Women get temporary relief of symptoms but drawback is-it cannot treat the underlying condition of estrogen deficiency.

Lubricants are administered before sex or as needed to reduce friction, whereas moisturizers are applied 1-3 days with longer effects [36].

Three types of lubricants are there- water based such as K$\mathrm{Y}$ jelly, silicon based and oil based like Vaseline, petroleum jelly, (Obstet Gynecol.1994; 82:215-18). Petroleum based lubricants can be irritating to the vagina, while water based lubricants dry the area of application without extended activity [37]. Both natural oil and silicon based lubricants are not irritating to the vagina but natural oil based lubricants cannot be used in women who have peanut allergy. Silicon based lubricants are also long lasting and waterproof [37]. Women should try various products until they find one that meets their needs and to find the one they like best.

Moisturizer Provide longer time relief, rehydrate dry vaginal tissues by changing the fluid content in the vaginal epithelium, absorbing and adhering to the epithelium, mimicking vaginal secretions and lowering the $\mathrm{pH}$, of the vagina but neither Lubricants nor moisturizers offer long term efficacy or convenient application, only a minority of women(breast cancer survivors) have reported being satisfied with these approaches and no elevated risk of de novo breast cancer with local estrogen therapy [36-38]. 


\subsection{Hormonal Treatment}

Considering the cause hypoestrogenism and the pathogenesis of the development of GSM/VVA most logical choice for the treatment of this is estrogen therapy. However most physician and scientific societies, they look for other options too. Replenishment of estrogen deficiency can be carried out with hormone preparation with systemic and local action. According to latest clinical guidelines topical estrogen is the drug of choice for GSM or vaginal dryness. Local estrogen therapy improves the thickness of the vaginal mucosa, reduces $\mathrm{pH}$ and increase vaginal maturation index and thereby improves the signs/ symptoms of GSM/VVA.

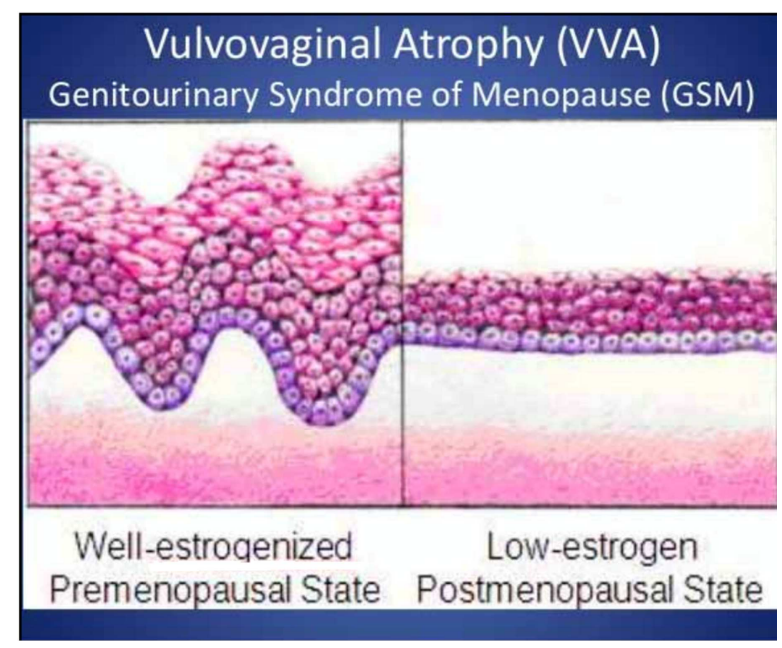

Figure 6. Histopathological changes of vaginal mucosa.

Curtsey of Adjuunct professor of LECOM, march 3,2018

Systemic hormone replacement therapy includes all the preparation containing estrogen of different preparation. Local estrogen is highly effective in reverting the physiological changes associated with GSM/VVA; it fosters vaginal cell growth and maturation, favors lactobacillus colonization and is preferred in the presence of isolated VVA. Effect of local estrogen therapy is usually achieved with in 13 months. Local estrogen therapy can be administered as vaginal tablets, vaginal cream or through vaginal ring. The choice of product can be based on clinical experience and patient's preference [38]. It could take weeks for symptoms relief, post treatment initiation and treatment should continue as long as patients feel discomfort from symptoms [39]. In comparison to cream, tablets carries reduced risk of systemic absorption, decreased leakage and may be better able to deliver a specific dose [40]. Another option -vaginal ring, may be difficult to insert, can be dislodged or may be felt by the partner during sex if not removed before intercourse. All the local estrogen alleviates GSM/VVA with similar efficacy [41]. Vaginal Estrogen therapy (ET) has beneficial effects also on urinary problems, meta-analysis of 14 studies showed ET that improved dysuria, urinary urgency, frequency, nocturia and incontinence [42] low dose ET is preferred to systemic ET if the goal is to treat GSM/VVA associated symptoms [43]. Adverse effect of vaginal estrogen is uncommon. Women may complain of vaginal irritation, slight vaginal bleeding but this is rare. (Cochrane database (2006) 2003/2005 (4) CD001500Pubmed).

Estrogen local cream is very effective; usually estradiol and conjugated equine estrogen are being used. Estradiol is dispensed in the form of tablet vagifem, cream, and ringestring. Estradiol local cream may be used 50 micro daily, premarin. $625 \mathrm{mg}$ once daily for two weeks and then can be used for twice in a week for three months. It may be used as long as 1 year. Very minimum amount of estrogen is absorbed in the system and that does not exceed the postmenopausal level of estradiol. This amount does not cause endometrial hyperplasia, therefore additional progestins are not recommended during the use of estrogen cream (Women health watch 2007; 15 (3): 7 [Pub Med]).

These low dose preparations are safe at least for short term. They don't spur any significant growth of endometrial cell when used up to 1 year. The estrogen ring and tablet don't boost blood level of estrogen significantly. The choice of the form of administration of the drug is determined by the patient's preference.

Nevertheless Lack of but any postmenopausal bleeding should be evaluated [35]. Unfortunately this highly effective ET remains under-prescribed, only with less than $10 \%$ of postmenopausal women being treated with ET ([44]. Systemic estrogen therapy also reduces symptoms by $75 \%$ on the other hand local estrogen reduces about $80-90 \%$. When systemic estrogen therapy is taken for menopausal symptoms, the improvement in well being with symptoms alleviation may result in improvement in libido as well as relief of GSM/VVA [45]. In addition, estrogen therapy is associated with urinary tract benefits. These include a reduction in the incidence of repeated urinary tract infections and overactive bladder symptoms. Urgency and stress incontinence, however, do not improve significantly with estrogen therapy alone. Testosterone Cream

Existing data provides some support for this cream for GSM/VVA as it stimulates vaginal mucosa and improves vaginal dryness by binding the androgen receptor (Fertiil Steril 2003; 79:925). A woman who is suffering from GSM and libido, testosterone is the choice of drug.

Vaginal Dehydroepiandrosteron (DHEA)

DHEA (Prasterone cream) is a prohormone in the biosynthetic pathway of testosterone and estradiol. It is novel in its conversion into estrogen and testosterone and has undergone robust and formal drug development to confirm its efficacy and safety. This cream penetrates vaginal wall better. It increases the $\mathrm{w}$ vaginal all thickness, elasticity and vascularity of vaginal wall. It improves dyspareunia and libido along with GSM/VVA (14). It does not stimulate the endometrium [2]. Labrie et al showed its beneficial effects on VVA and it improves dyspareunia and dramatically improves GSM [28]. Study by Barbara Hoffman expressed high satisfaction of women with DHEA. Daily dose of intravaginal application of DHEA $(6.5 \mathrm{mg})$ has shown favorable effects for vaginal dryness and dyspareunia, but these effects are not sustained when it is given twice in a week and RCTs 
have not shown benefits of its effect on systemic therapy. In both pivotal trials, treatment with intra-vaginal Prasterone (DHEA) was associated with reduction in moderate to severe dyspareunia for women with menopause, compared to placebo,(-1'27, 0'40 severity score units over placebo, 46\%; $\mathrm{p}=0.003)$ and $(-1.420$ '36 severity score units over placebo, $34 \% \mathrm{p}=<0$ '0002) in pivotal trial 1 and 2 respectively [46]. Regarding endometrial safety -multicenter, placebo controlled trial showed atrophy or inactive endometrium, found from histopathology obtained from users of parestone with no proliferation or hyperplasia of endometrium, confirming lack of stimulatory effect of intra-vaginal praesterone [47]. Many postmenopausal women suffering with GSM/VVA identify painful intercourse is the most bothersome symptom. Prasterone can provide a safe, effective and innovative approach to this common and often debilitating condition.

\subsection{Non-Hormonal Treatment}

Ospemifene is a SERM (selective estrogen receptor modulator), used $60 \mathrm{mg} /$ day. It is albeit a systemic non- hormonal therapy, acts locally as an estrogen. It interacts with intracellular estrogen receptors in the target organs as agonist or antagonist. It has agonist effect on vaginal epithelium. Its antagonist effect on endometrium and breast makes it unique and safe; it has no estrogenic effect here. It is the best option when women have contraindication for estrogen, FDA approved Osmpemifene for the treatment of moderate to severe dyspareunia caused by GSM/VVA in menopausal women [2]. Beauty of Ospemiphene is that it can improve sexual function (desire, arousal, orgasm, lubrication, satisfaction and reduced pain) in postmenopausal women with GSM/ VVA [48]. It is safe and very effective but better to avoid in women who has risk of thromboembolism [25]. Ospemifene is well tolerated in short and long-term use. Endometrium remains atrophic after 12 months use and 2.2\% reduction in incidence of breast abnormality and there is no cardiovascular risk. (Menopause 2010; 17:642-53). In addition Ospemifene reduces the bone turnovers. Lasofoxifene is a new third generation SERM. It also binds both receptor and it shows same efficacy, but not yet approved by FDA.

\begin{tabular}{|c|c|c|c|}
\hline Treatment type & Specific therapy & Typical use & Notes \\
\hline Education & $\begin{array}{l}\text { Educate regarding potential vulvar and } \\
\text { vaginal changes associated with } \\
\text { menopause or other low estrogen } \\
\text { state; offer therapy as indicated }\end{array}$ & & $\begin{array}{l}\text { Education should be offered to women } \\
\text { regardless of partner status; regular } \\
\text { painless sexual activity or vaginal stim- } \\
\text { ulation can help maintain sexual func- } \\
\text { tion }\end{array}$ \\
\hline Counseling and sex therapy & $\begin{array}{l}\text { Cognitive behavioral therapy; mindful- } \\
\text { ness exercises }\end{array}$ & & $\begin{array}{l}\text { Counseling or sex therapy with a qualified } \\
\text { counselor/therapist may be useful for } \\
\text { women with dyspareunia or relationship } \\
\text { discord. AASECT org }\end{array}$ \\
\hline Lubricants & $\begin{array}{l}\text { Water-based } \\
\text { Silicone-based } \\
\text { Oil-based }\end{array}$ & Used as needed for sexual activity & $\begin{array}{l}\text { Used to increase comfort and pleasure; } \\
\text { avoid potential irritants (eg, glycerin, } \\
\text { parabens, propylene glycol); can be } \\
\text { used with other therapies (hormone and } \\
\text { nonhormone) }\end{array}$ \\
\hline Moisturizers & & $\begin{array}{l}\text { Used daily or every few days on a } \\
\text { regular basis independent of } \\
\text { sexual play to maintain vulvar } \\
\text { and vaginal moisture }\end{array}$ & $\begin{array}{l}\text { Mimics normal vaginal secretions; does } \\
\text { not restore or reverse cellular/pH } \\
\text { changes of GSM; can be used with } \\
\text { other therapies (hormone and nonhor- } \\
\text { mone) }\end{array}$ \\
\hline Self-stimulators/Vibrators & $\begin{array}{l}\text { May be a variety of materials (eg, } \\
\text { latex, nonlatex, silicone, hard } \\
\text { plastic) }\end{array}$ & $\begin{array}{l}\text { Can be used as needed during } \\
\text { sexual play, alone, or with } \\
\text { partner }\end{array}$ & $\begin{array}{l}\text { Gently stimulates vulvar and vaginal tis- } \\
\text { sues; may facilitate natural lubrication; } \\
\text { may help maintain function }\end{array}$ \\
\hline Dilators & $\begin{array}{l}\text { May be a variety of materials (eg, } \\
\text { plastic, silicone, glass) }\end{array}$ & $\begin{array}{l}\text { Ideal duration or frequency of use } \\
\text { is unknown }\end{array}$ & Stretches vaginal tissues \\
\hline Pelvic floor physical therapy & $\begin{array}{l}\text { Examples: education on kinesthetic } \\
\text { awareness; pelvic floor muscle } \\
\text { relaxation; manual therapies; } \\
\text { biofeedback }\end{array}$ & $\begin{array}{l}\text { Used as needed for nonrelaxing } \\
\text { pelvic floor muscle dysfunction }\end{array}$ & $\begin{array}{l}\text { Identify a physical therapist who specia- } \\
\text { lizes in pelvic floor disorders www.wo- } \\
\text { menshealthapta.org/ }\end{array}$ \\
\hline
\end{tabular}

AASECT, American Association of Sexuality Educators, Counselors, and Therapists; GSM, genitourinary syndrome of menopause. Adapted from Faubion S, et al. ${ }^{55}$

4 Menopause, Vol. 25, No. 6, 2018

(C) 2018 The North American Menopause Society

Figure 7. Non Hormonal Therapy for VVA.

\section{LASER THERAPY}

It is newer Option of treatment for GSM/VVA. There are very few options available, local ET seems superior to others but still not very much effective in compare to placebo. Kozma et al confidently concluded from their study that fractional $\mathrm{CO} 2$ Laser is an effective and safe treatment of symptoms associated with GSM [49]. In addition REVIVE study suggests women are concern about long-term use and safety of vaginal ET [50]. In that context Laser therapy is very promising. Laser technology delivers fractional $\mathrm{CO}_{2}$ and non-ablative photo thermal Er; YAG to the vaginal wall. Both the group is simple, faster, and painless procedure. They differ in wavelength, water absorption and tissue penetration. Both activate dominant fibroblasts thereby increase collagen tissue, proteoglycans and hyaluronic acid inside the vagina. Therefore water is retained in vagina and blood supply to vaginal mucosa becomes normal. Laser therapy replenishes glycogen in the vaginal mucosa and allows restoring $\mathrm{pH}$ balance of mucosa and therefore improves the symptoms of atrophy and improves sexuality [29]. The Salvatore study showed $85 \%$ women regained sexuality within 12 weeks of laser therapy [33]. Long-term data showed that improvement 
of vaginal health may continue up to 24 months after fractional $\mathrm{CO}_{2}$ and $80 \%$ women decided to start a new treatment cycle of laser applications. Laser therapy has demonstrated high satisfaction among patients and health care providers. MHT can provide quick and long term relief while urinary symptoms often requires additional effective therapy [51]. A recent systemic review and meta-analysis of 14 observational studies found that all GSM/VVA symptoms and urinary incontinence decreased significantly and marked improvement in sexual function [52] with laser treatment.

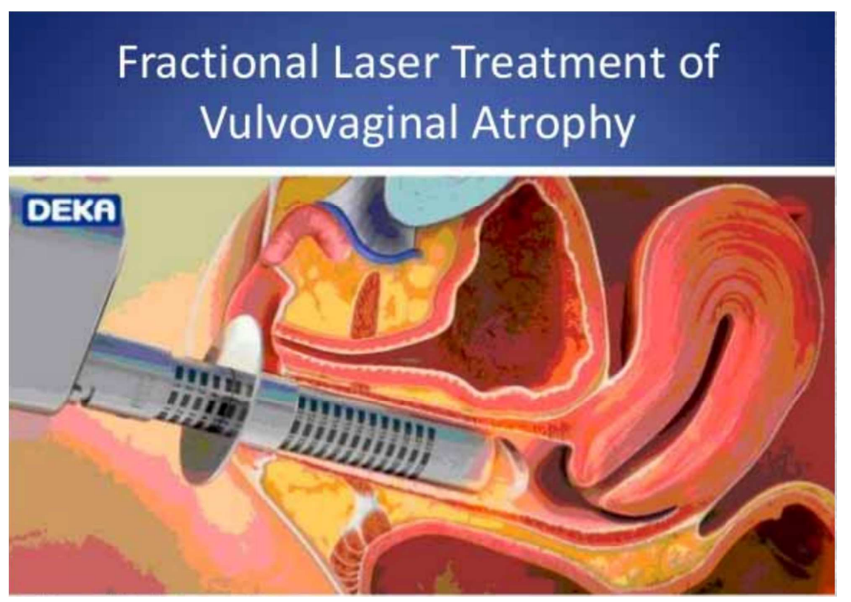

Figure 8. Technique of laser administration.

Women need to choose, considering the benefits and risks associated with each strategy. A systematic review and met analysis reported that, despite the lack of well designed controlled studies, laser intervention appears to be safe and potentially effective non pharmacological intervention for GSM/VVA. It induces significant improvement of vaginal health [53].

Newer generation of laser

Erbium laser is non-ablative photo thermal therapy is very effective but ACOG not yet recommended its use. L Cardozo et-al conducted the 1st randomized single blind, multicenter study of both types laser, which proved safety and efficacy of laser treatment for GSM/VVA. Therefore it can be said that Vaginal laser have been shown to restore the virginal's physiology and effectively treat GSM /VVA [54].

\section{Effect of Laser}

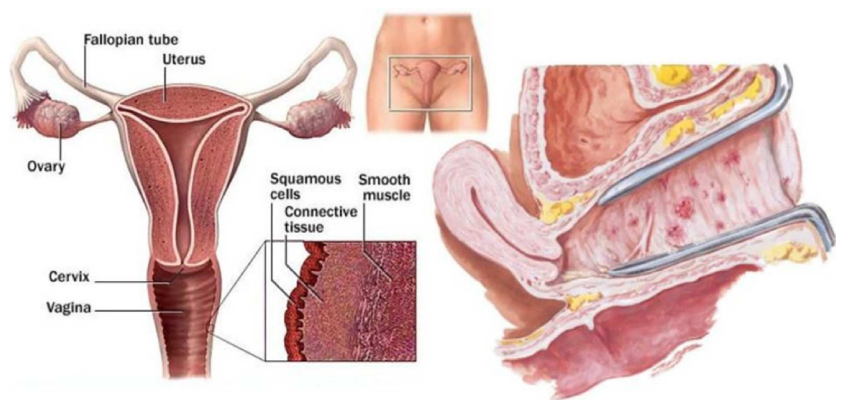

Figure 9. Improvement of vaginal mucosa.
Other Non hormonal therapy-Antidepressant, Gabapentin, Serotonin reuptake inhibitors, Nor-epinephrine reuptake inhibitors, usually has role to diminish the vasomotor symptoms, but their role for VVA or GSM is not that good.

Plants like Soya (isoflavin), black cohosh, Red clover, Chinese herbs like tofu, mace and flaxseed are used for reliving the other menopausal symptoms. GSM/VVA is unlikely to respond to these drugs. They are not yet evidenced based.

Probiotics

Oral Vit D and vaginal vitamin $\mathrm{E}$ increases moisture of vagina but efficacy data are limited. Oral and Vaginal probiotics suppose to alter microbial in favor of GSM/VVA but comprehensive trials are needed for validation [55].

\section{Pelvic Physical Therapy}

Women who do not respond to conventional therapies or hormone is contraindicated physical therapy may be the choice. Vaginal dilators are the component of physical therapy it may be used in case of vaginal stenosis or shortening of vagina. Some data suggest that dilators improve vaginal function [56] but again it cannot restore the hypo estrogenic effect in vagina.

G-Shot; rejuvenate the orgasm system by stimulating stem cell, found in tissue of vagina \& clitoris. PRP (plasma rich protein), Botox are being used, many women may get good respond but these treatments for GSM or VVA are not yet evidence based.

\section{Future}

There is significant unmet need for medical treatment of Vulvovaginal atrophy or GSM.

\section{Conclusion}

VVA or GSM may need not to be an inevitable consequence of menopause. Active diagnosis and intervention may prevent its adverse impacts and progression. A careful history, physical examination is essential in ruling out other vulvovaginal conditions and determining the range and severity of GSM. Women may remain silent, though few women may report but that is only tip of iceberg. Health providers need to break the iceberg of silence and offer full information about different options of treatments of VVA or GSM. All women have right to lead a quality life, so health provider should not only have wide knowledge about the management of GSM/VVA but they need to be very kind and should have empathy. Shared decision-making between physician and patients is the of key of success to address GSM/VVA.

\section{Conflict of Interest}

All the authors do not have any possible conflicts of interest. 


\section{References}

[1] Labrie F, Belanger A, Pelletier G, et al. Science of intracrinology in postmenopausal women. Menopause 2017; 24: $702-12$.

[2] Davis SR, Davison SL, Donath S, et al. Circulating androgen levels and self-reported sexual function in women. JAMA 2005; 294: 91-6.

[3] Krychman M, Graham S, Bernick B, Mirkin S, Kingsburg SA. The women's EMPOWER survey; women's knowledge and awarness of treatment options for vulvar and vaginal atrophy remains inadequate Sex Med 2017; 14; 425-33.

[4] Erekson EA, Li FY, Martin DK, et al. Vulvovaginal symptoms prevalence in postmenopausal women and relationship to other menopausal symptoms and pelvic floor disorders. Menopause 2016; 23: 363-75.

[5] Nappi RE, Palacios S. Impact of vulvovaginal atrophy on sexual health and quality of life at postmenopause. Climacteric 2014; 17: 3-9

[6] Calleja-Agius J, Brincat MP. Urogenital atrophy. Climacteric 2009; 12: 279-85.

[7] Lara LA, Useche B, Ferriani RA, et al. The effects of hyopoestrigenism on the vaginal wal: interference with the normal sexual response: J Sex Med 2009; 6: 30-9

[8] Wysoki S, Kingsberg S, Krychman M. Management of vaginal atrophy: implications from the REVIVE Survey. Clin Med Insights Reprod Health 2014; 8: 23-30.

[9] Santoro N, Komi. Prevalence and impact of vaginalsymptoms among postmenopausal women. J Sex Med 2009; 6: 2133-42.

[10] Santoro N, Sherman S. New interventions for Menopausal symptoms. Bethesda MD: National institute ofs of health, UD Dept of Health and Huma Services, 2006.

[11] Portman DJ, Gass ML, Vulvovaginal Atrophy Terminology Consensus Conference Panel. Genitourinary Syndrome of menopause: New Terminology For Vulvovaginal Atrophy From The International Society for the Study of Women' Sexual Health and The North American Menopause Society. Climacteric 2014; 17; 557-63.

[12] M. Shaprio; What should guide our patient management of vulvovaginal atrophy?; CILMACTERIC, 2019; volume 22; number $1 ; 38-43$.

[13] Baber RJ, Panay n, Fenton A; IMS Writing u group. 2016 ims Recommendation on women's midlife health and menopause hormone therapy Climacteric 2016; 19; 109-50.

[14] Freedman MA. Perceptions of dyspareunia in postmenopausal women with vulvar and vaginal atrophy: findings from the REVIVE survey. Womens Health (Lond Engl) 2014; 10: 44554.

[15] Barton DL, Shuster LT, Dockter T, et al. Systemic and local effects of vaginal dehydroepiandrosterone (DHEA): NCCTG N10C1 (Alliance). Support Care Cancer 2018; 26: 1335-43.

[16] Willhite LA, O'Connell MB. Urogenital atrophy: prevention and treatment. Pharmacotherapy 2001; 21: 464-80.
[17] Meisels A. The menopause: a cytohormonal study. Acta Cytol 1966; 10: 59-55.

[18] Nappi RE, Cucinella L, Martella S, Female sexual dysfunction (FSD); prevalence and impact on quality of life. Maturitas 2016; 94: 87-91.

[19] Worsley R Bell RJ, Gartoulla P, Davis SR, Prevalence and predictors of low sexual desire, sexuality related personal distress and hypoactive sexual desire dysfunction in a community based sample of midlife women. J Sex Med 2007; 14: 675-86.

[20] Sidi H, Puteh SE, Abdullah N, Midin M, The prevalence of sexual dysfunction and potential risk factors that may impair sexual function in Malaysian women. J Sex Med 2007; 4: 311-21.

[21] Johnston S. Urological concerns J Obstet Gynecol Can 2006; 28: 533-542.

[22] North American Menopause Society. The role of local vaginal estrogen for the treatment of vaginal atrophy in post menopausal women.2007 position statemen of the North American Society of Menopause2007; 14: 355-69.

[23] Mac Bride MB, Rhodes DJ, Shuster LT. Vulvovaginal atrophy. Mayo Clin Proc 2010;85: 87-94.

[24] Nappi RE, Lachowsky M. Menopause and sexuality; prevalence of symptoms and impact on quality of life. Maturitas; 2009: 63; 138-41.

[25] Palma F, Volpe P, Cagnacci A; as the writing Gropu of the AGATA STUDY. Vaginal atrophy of women in postmenopause. Results from multicentric observational study: The AGATA study. Maturitas 2016; 83: 40-4.

[26] Kingsberg SA, Wysocki S, Magnus L, Vulvar and vaginal atrophy in postmenoausal women; findings from REVIVE survey, J Sex Med 2013; 10: 1790-9.

[27] Simon JA, Komi J, Postmenopausal women's attitude: Vulvovaginal atrophy and it's symptoms. (NAMS Abstract LB-10) Menopause 2007; 14: 1107.

[28] Goldstein I, Recognizing and treating urogenital atrophy in postmenopausal women. J Women's health (Larchmt) 2010; 19: 425-32.

[29] Nappi RE, NRd demelo, M Martiso, C Celis, Gonzaliz. VIVA study, Climacteric 2018, vol 21. No 4, page 397-403.

[30] Kingsberg SA, Wysocki S, Magnus L, et al. Vulvar and vaginal atrophy in postmenopausal women: findings from the REVIVE (REal Women's VIews of Treatment Options for Menopausal Vaginal ChangEs) survey. J Sex Med 2013; 10: 1790-9.

[31] 27Kingsberg SA, Krychman M, Graham S, et al. The women's EMPOWER survey: identifying women's perceptions on vulvar and vaginal atrophy and its treatment. $\mathrm{J}$ Sex Med 2017; 14: 413-24.

[32] Kingsberg SA, Krychman ML. Resistance and barriers to local estrogen therapy in women with atrophic vaginitis. J Sex Med 2013; 10: 1567-74.

[33] Chua Y, Lympaphayom KK, Cheng B, et al. Genitourinary syndrome of menopause in five Asian countries; results from the Pan Asian REVIVE survey, Climacteric 2017; 20: 73. 
[34] Simon JA, Nappi RE, Kingsberg SA, Maamari R, Brown V. Clarifying vaginal Atrophy's impact on sex and relationship (CLOSER) survey; emotional and physical impact of vaginal discomfort on North America postmenopausal women their partners. Menopause 2014; 21: 137-42.

[35] The North American Menopause Society. Management of symptomatic vulvovaginal atrophy: 2013 position statement of The North American Menopause Society. Menopause 2013; 20: 888-902.

[36] Kingsberg S, Wysocki S, Magnus L, Krychman ML. Vulvar and vaginal atrophy in postmenopausal women: findings from the REVIVE (REal Women's VIews of Treatment Options for Menopausal Vaginal ChangEs) survey. J Sex Med 2013; 10: 1790-9.

[37] Hutcherson HY, Kingsberg SA, Krychman ML, et al. A positive approach to female sexual health: a summary report. Female Patient 2009; (Suppl April): 1-4.

[38] Crandall CJ, Hovey KM, Andrews CA, et al. Breast cancer, endometrial cancer, and cardiovascular events in participants who used vaginal estrogen in the Women's health initiative Observational study. Menopause 2018; 25: 11-20..

[39] The North American Menopause Society. The role of local vaginal estrogen for treatment of vaginal atrophy in postmenopausal women: 2007 position statement of The North American Menopause Society. Menopause 2007; 14: 357-69.

[40] Bachmann G, Lobo RA, Gut R, Nachtigall L, Notelovitz M. Efficacy of low-dose estradiol vaginal tablets in the treatment of atrophic vaginitis: a randomized controlled trial. Obstet Gynecol 2008; 111: 67-76.

[41] Lethaby A, Ayeleke R, Roberts H. Local oestrogen for vaginal atrophy in postmenopausal women. Cochrane Database Syst Rev 2016; 8: CD001500.

[42] Rahn DD, Carberry C, Sanses TV. Vaginal estrogen for genitourinary syndrome of menopause. Obstet Gynecol 2014; 124: $1147-56$.

[43] Archer DF. Efficacy and tolerability of local estrogen therapy for urogenital atrophy. Menopause 2010; 17: 194-203.

[44] Zeleke BM, Bell RJ, Billah B, Davis SR. Vasomotor and sexual symptoms in older Australian women: a cross-sectional study. Fertil Steril 2016; 105: 149-55. e1 41.
[45] Santoro N, Worsley R, Miller KK, Parish SJ, Davis SR. Role of estrogens and estrogen-like compounds in female sexual function and dysfunction. J Sex Med 2016; 13: 305-16.

[46] Labrie F, Archer DF, Kolitun W, et al. Efficacy of intra vaginal dehydroepiadrosterone (DHEA) on moderate to severe dyspareunia and vaginal dryness, symptoms of vulvovaginal atrophy, and of the genitourinary syndrome of menopause. Menopause 2016; 23: 243-56.

[47] Simio JA, Goldstein I, Kim NN, et al. The role of androgen in the treatment of genitourinary syndrome of menopause (GSM); International society for study of women's Sexual health, expert consensus panel review. Menopause; 2018; 25; 837-47.

[48] Constantine G, Graham S, Portman DJ, Rosen RC, Kingsberg SA Female sexual function improved with ospemifene in postmenopausal women with vulvar and vaginal atrophy: results of a randomized, placebo-controlled trial. Climacteric 2015; 18: 226-32.

[49] Kozma B, et al. Orv Hetil. 2019; 160: (41): 1617-1622.

[50] Nappi RE, Palacios S, Panay N, et al. Vulvar and vaginal atrophy in four European countries: Evidence from the European REVIVE survey. Climacteric 2016; 19: 188-97.

[51] Giarenis I, Cardozo L. Managing urinary incontinence: Whay works? Climacteric 2014; 17 (suppl 2) 26-33.

[52] Salvatore S, Nappi RE, Parma M, et al. Sexual function after fractional microablative $\mathrm{CO}_{2}$ laser in women with vulvovaginal atrophy. Climacteric 2015; 18: 219-25.

[53] Salvator S, Nappi RE, Zerbinati N, et-al. A 12 week treatment with fractional $\mathrm{CO}_{2}$ laser for vulvo-vaginal atrophy: a pilot study. Climacteric 2014; 17: 363-9.

[54] Pitsouni E, Grigoriadis T, Falagas ME, et al. Laser therapy for genitourianry syndrome of menopause. A systematic review and meta-analysis. Maturitas 2017; 103: 78-88.

[55] Muhleisen AL, Herbst Kralovertz MM. Menopause and the vaginal microbiom. M aturitas 2016; 91: 422.

[56] Carter J, Goldfrank D, Schover LR. Simple straties for vaginal health promotion in cancer survivors. J Sex Med 2011; 8; 549. 